\title{
RANCANG BANGUN SISTEM INFORMASI MANAJEMEN PERPUSTAKAAN PADA BADAN PERPUSTAKAAN DAERAH KOTA KUPANG
}

\author{
Mardhalia Saitakela
}

\begin{abstract}
Abstrak :
Perpustakaan adalah salah satu tempat akses informasi yang sangat penting. Salah satu langkah agar berhasil dan tidaknya berbagai macam proses yang dilakukan seseorang maka perlu adanya kegiatan membaca, oleh karena itu perlu dikembangkan budaya giat membaca bagi masyarakat Indonesia pada umumnya sehingga bisa lebih maju satu langkah kedepan.

Perpustakaan daerah Kota Kupang masih banyak kekurangan dalam hal manajemen pengelolaan yang berhubungan dengan pengelolaan buku. Semua pengelolaan kegiatan peminjaman dan pengembalian buku masih dilakukan dengan pencatatan biasa oleh petugas pada satu buku induk perpustakaan, hal ini sangat memakan waktu yang cukup lama dan tidak efisien serta sulitnya petugas mengetahui jenis dan jumlah buku yang belum dikembalikan oleh peminjam. Solusi untuk menyelesaikan permasalahan tersebut adalah dengan membangun aplikasi yang dapat membantu petugas dalam hal mempermudah dalam proses pencatatan daftar buku serta pencarian informasi ketersediaan buku dan pengembalian buku oleh peminjam serta dapat melihat banyaknya minat pembaca yang menggunakan fasilitas perpustakaan.

Hasil yang diperoleh dari penelitian ini adalah berupa aplikasi manajemen perpustakaan pada badan perpustakaan daerah Kota Kupang.
\end{abstract}

Kata kunci : Sistem Informasi, Manajemen, Perpustakaan.

\section{PENDAHULUAN}

Perpustakaan adalah salah satu tempat akses informasi yang sangat penting. Salah satu langkah agar berhasil dan tidaknya berbagai macam proses yang dilakukan seseorang maka perlu adanya kegiatan membaca, oleh karena itu perlu dikembangkan budaya giat membaca bagi masyarakat Indonesia pada umumnya sehingga bisa lebih maju satu langkah kedepan. Pemerintahan Kota Kupang dalam mengembangkan sumber daya manusia telah menyediakan perpustakaan daerah yang dapat dimanfaatkan sebagai tempat menuai ilmu pengetahuan bagi masyarakat baik mahasiswa, siswa sekolah maupun kelompok masyarakat umum lainnya, salah satu perpustakaan yang disediakan pemerintah di Provinsi Nusa Tenggara Timur adalah Perpustakaan Daerah Kota Kupang yang beralamatkan di Jln. SK. Lerrik No 1 Kota Baru Kupang. Penyediaan perpustakaan daerah ini dilakukan demi mewujudkan otonomi daerah yang memiliki sumber daya manusia yang memadai. Banyak ilmu pengetahuan yang dapat dipetik jika rajin membaca, wawasan masyarakat akan bertambah luas ditambah dengan penyediaan buku-buku yang biasa dipinjam secara gratis karena perpustakaan daerah merupakan salah satu program pemerintah untuk meningkatkan daya tarik membaca masyarakat dan memperluas ilmu pengetahuan. Manajemen Perpustakaan merupakan kesinambungan kerja dari unsur- 
unsur perpustakaan meliputi petugas, peminjam atau anggota sampai pada buku itu sendiri. Pengolahan manajemen perpustakaan yang baik menggunakan aplikasi pada Perpustakaan Daerah Kota Kupang akan sangat mendukung program pemerintah yang disebutkan di atas sehingga semua masyarakat dapat menikmati pengetahuan di luar bangku pendidikan secara merata. Masih banyak kekurangan dalam hal manajemen pengelolaan buku-buku baik pengelolaan peminjaman maupun pengembalian buku oleh masyarakat. Pencatatan, daftar buku, peminjaman dan pengembalian buku masih dilakukan dengan pencatatan biasa oleh petugas pada satu buku induk perpustakaan hal ini sangat memakan waktu yang cukup lama dan tidak efisien serta sulitnya petugas mengetahui jenis dan jumlah buku yang belum dikembalikan oleh peminjam dikarenakan tidak diberlakukan denda bagi peminjam yang terlambat mengembalikan buku. Solusi untuk menyelesaikan permasalahan tersebut adalah dengan membangun aplikasi yang dapat membantu petugas dalam hal mempermudah dalam proses pencatatan daftar buku serta pencarian informasi ketersediaan buku dan pengembalian buku oleh peminjam serta dapat melihat banyaknya minat pembaca yang menggunakan fasilitas perpustakaan.

\section{METODE PENELITIAN}

\subsection{Metode pengumpulan data}

a. Studi Pustaka

Dilakukan dengan mencari literatur pendukung penelitian yang mampu memberikan informasi yang memadai dalam menyelesaikan penelitian

b.Metode Observasi Observasi dilakukan dengan cara mengadakan pengamatan langsung terhadap suatu objek yang akan diteliti yaitu pada Badan Perpustakaan Daerah Kota Kupang.

\subsection{Metode Perancangan Sistem}

Untuk membuat aplikasi manajemen perpustakaan pada badan perpustakaan Kota Kupang, perancangan sistem menggunakan metode terstruktur yaitu bagan alir (Flowchart), diagram konteks, dan ER-D.

a. Flowchart sistem aplikasi

Flowchart dokumen merupakan bagan yang menunjukkan arus dokumen dalam formulir atau menggambarkan prosedur di dalam sistem. Flowchart dokumen menunjukkan alur didalam program atau prosedur sistem secara logika (Kristanto, 2003), seperti terlihat pada gambar 1.

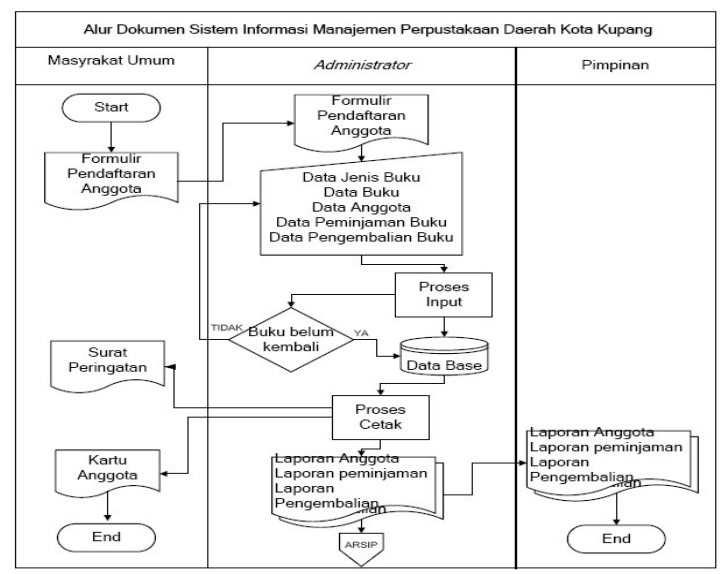

Gambar 1. Flowchart

\section{b.Diagram Konteks}

Diagram konteks adalah diagram yang terdiri dari suatu proses dan menggambarkan ruang lingkup suatu sistem (Fathansyah, 2007). Dari defenisi ini dapat disimpulkan bahwa diagram konteks adalah diagram yang menggambarkan alur ruang lingkup dari suatu sistem dan terdiri dari dokumen-dokumen serta fungsi-fungsi terkait. Seperti terlihat pada gambar 2.

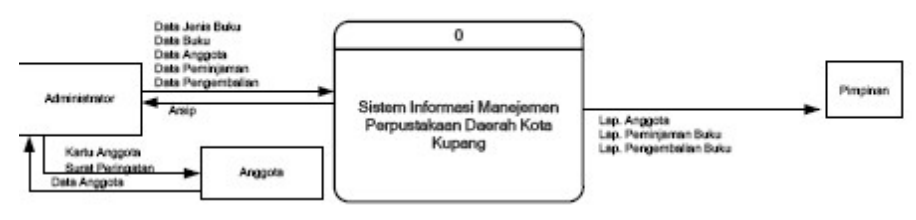

Gambar 2. Diagram Konteks 
c. Entity Relationship Diagram (ER-D)

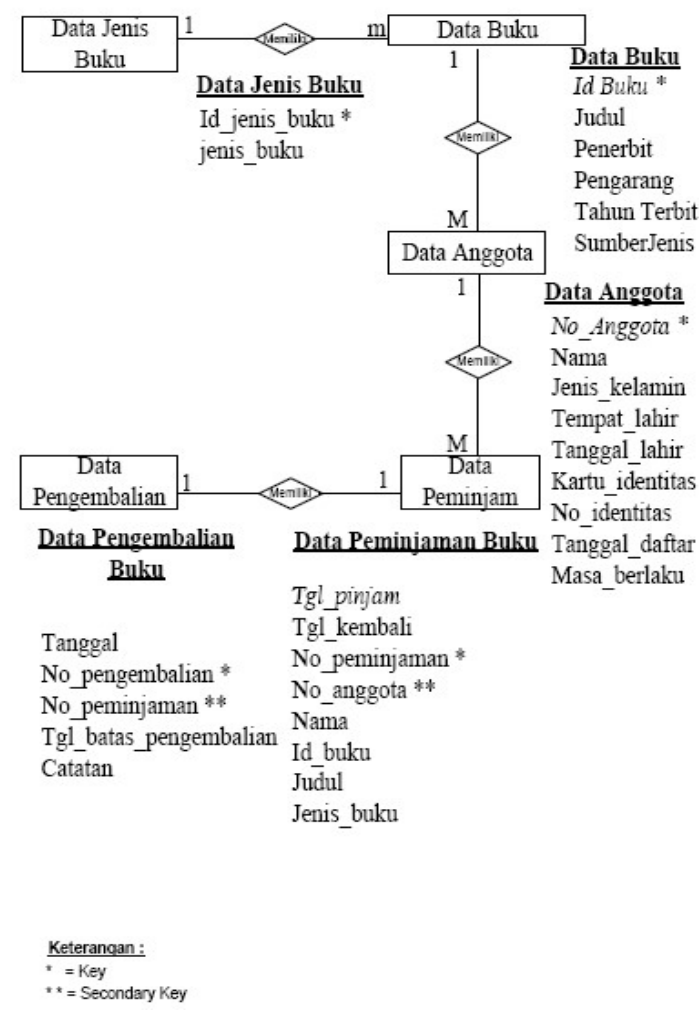

Gambar 3. Entity Relationship Diagram (ER-D)

\section{HASIL DAN PEMBAHASAN}

Berikut merupakan pembahasan hasil perancangan yang dibuat dalam bentuk Aplikasi :

\subsection{Menu Utama}

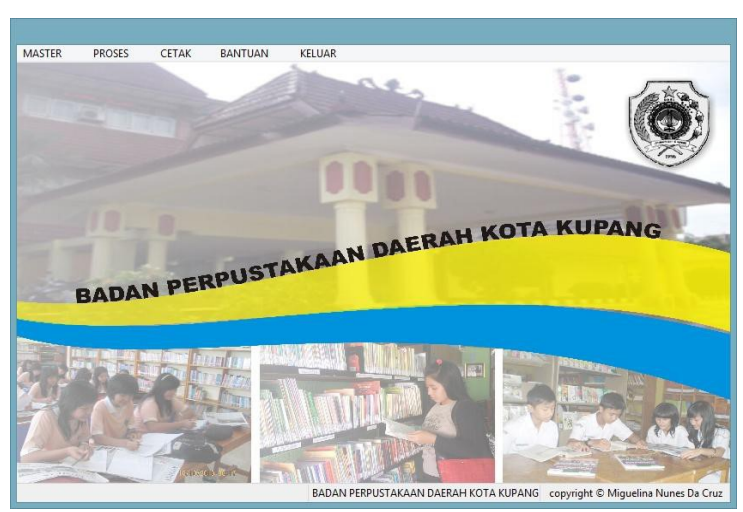

Gambar 4. Menu utama
Di dalam master data terdapat tiga tombol, yaitu data jenis buku, data buku, dan data anggota.

a. Form Jenis Buku, form ini digunakan untuk memasukan data-data jenis buku seperti pada gambar 5 .

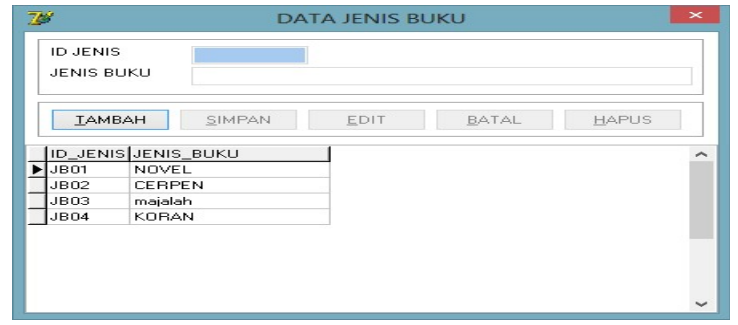

Gambar 5. Tampilan form data jenis buku

b. Form Buku, form ini digunakan untuk memasukan data-data buku

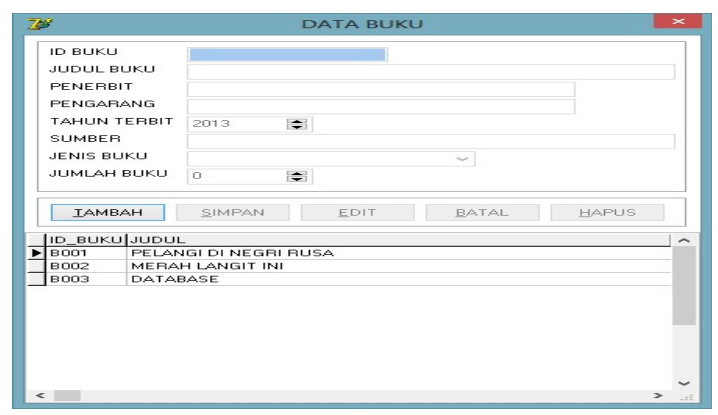

Gambar 6. Tampilan form data buku

c. Form Anggota, form ini digunakan untuk memasukan data anggota yang ada di Badan Perpustakaan Daerah.

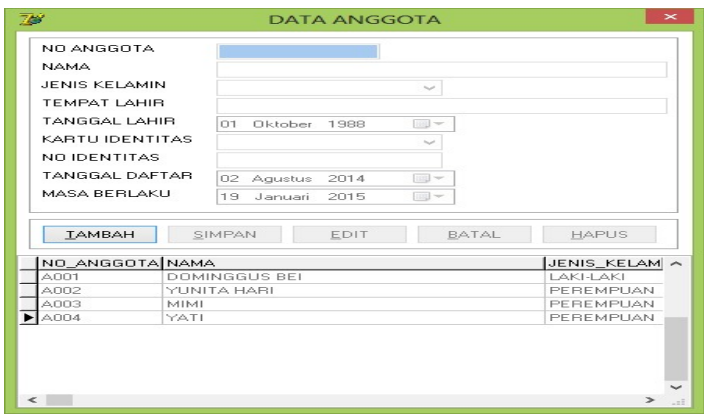

Gambar 7. Tampilan Form data anggota 


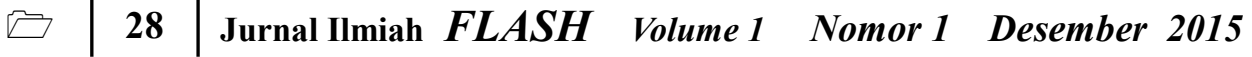

d. Form Peminjaman, digunakan untuk memasukan data peminjaman

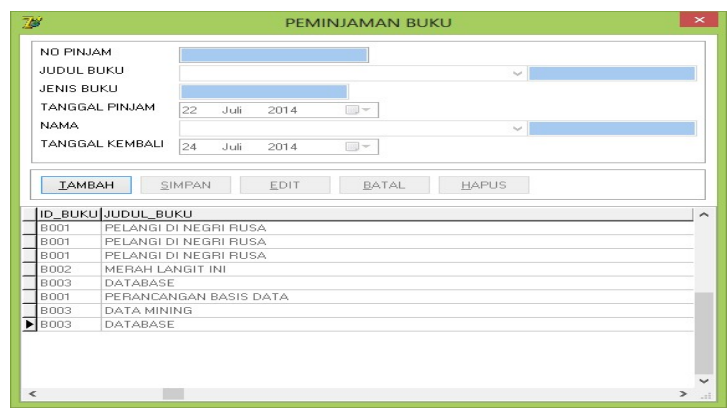

Gambar 8. Tampilan form data peminjaman buku

e. Form Pengembalian, digunakan untuk memasukan data pengembalian buku.

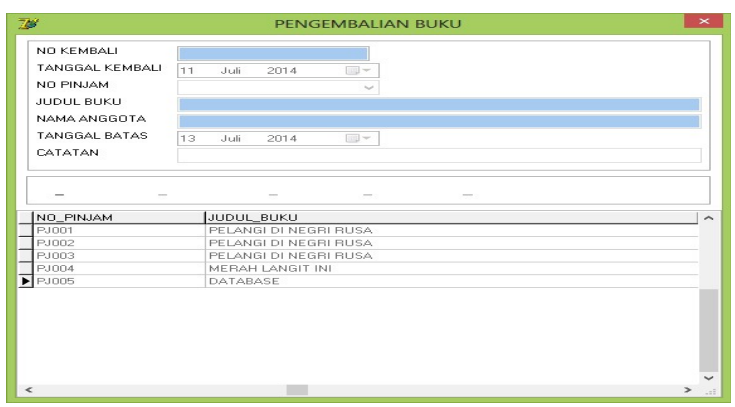

Gambar 9. Tampilan form pengembalian buku

f. Tampilan cetak laporan

\begin{tabular}{|l|l|}
\hline CETAK I BANTUAN \\
\hline DATA ANGGOTA \\
DATA PEMINJAMAN \\
DATA PENGEMBALIAN \\
KARTU ANGGOTA \\
SURAT PEMBERITAHUAN \\
\hline
\end{tabular}

Gambar 10. Cetak laporan g. Tampilan cetak laporan anggota.

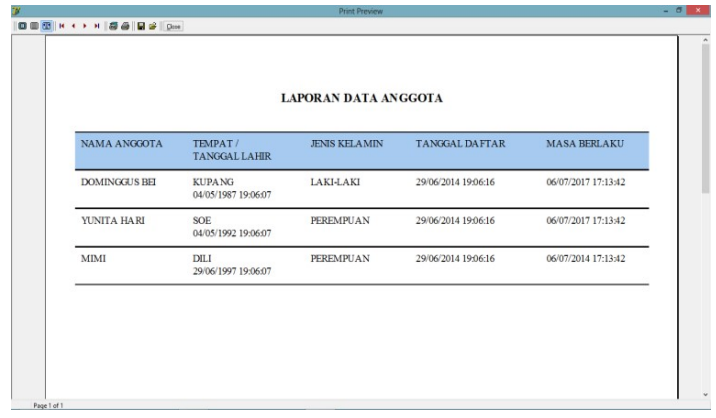

Gambar 11. Tampilan cetak laporan anggota

h. Tampilan cetak laporan peminjaman

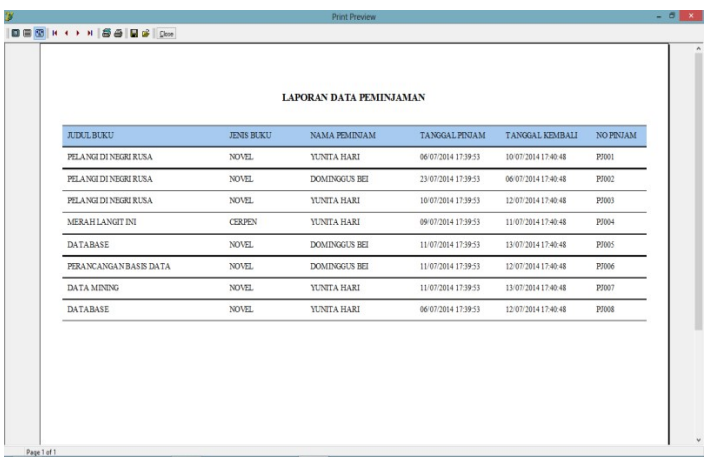

Gambar 12. Cetak laporan peminjaman

i. Tampilan Laporan pengembalian.

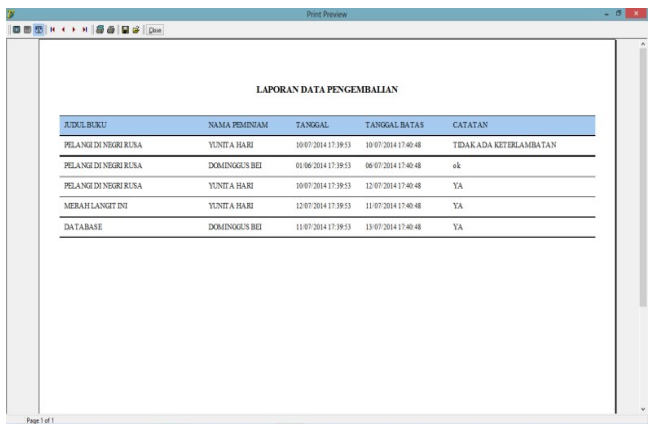

Gambar 13. Laporan pengembalian 
j. Tampilan cetak kartu anggota

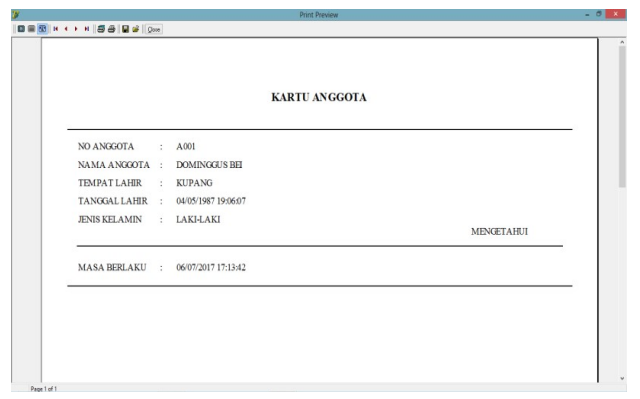

Gambar 14. Cetak kartu anggota

\section{KESIMPULAN}

Dengan adanya Sistem Informasi Manajemen perpustakaan diharapkan dapat memberikan kemudahan pada Badan Perpustakaan Daerah Kota Kupang dalam mendata buku, membuat kartu anggota, mendata peminjaman dan mendata pengembalian buku serta dapat menyediakan laporan data jenis buku, laporan data buku yang ada pada perpustakaan, laporan data peminjaman buku laporan data pengembalian buku

\section{SARAN}

Sistem informasi Manajemen perpustakaan yang dapat dikembangkan dengan berbasis online sehingga dapat dengan mudah diakses oleh siapa saja selama terhubung dengan jaringan internet.

\section{DAFTAR PUSTAKA}

[1] Fathansyah, 2007, Basis Data, Andi Offset, Yogyakarta.

[2] Kadir Abdul, 2007, Pemrograman Database dengan Delphi 6 menggunakan Access, Andi, Yogyakarta.

[3] Kristanto Andri, 2003, Perancangan Sistem Informasi Dan Sistem Aplikasinya, Gavamedia, Yogyakarta.

[4] Siaga, Sondang P., , 2011 Sistem Informasi Manajemen, Bumi Aksara, Jakarta.

[5] Sutabri Tata, , 2009, Analisis Sistem Informasi, Penerbit Andi, Yogyakarta. 